\title{
Knowledge, Attitude and Practice on Cytotoxicity of Intracanal Medicaments Among Dental Students
}

\author{
Preethi Mariona', S.Delphine Priscilla Antony², \\ ${ }^{1}$ Saveetha Dental College and Hospitals, Saveetha Institute Of Medical \\ and Technical Science (SIMATS), Saveetha University,Chennai-77 India \\ ${ }^{2}$ Senior Lecturer Department of Conservative Dentistry and Endodontics Saveetha Dental College and Hospitals, \\ Saveetha Institute Of Medical and Technical Science (SIMATS), Saveetha University, Chennai-77 India
}

\begin{abstract}
The main objective of a root canal treatment is to get rid of bacteria inside the root canal treatment. Placement of an intracanal medicament is an integral step in the treatment procedure. Cytotoxicity is a characteristic of being toxic to cells.In some cases if the intracanal medicament extrudes beyond the root canal, it is seen to cause damage to the cells of the periapical tissues that subsequently lead to the damage or inflammation of the periapical region. This study aims at assessing the knowledge, attitude and practice among dental undergraduates on the cytotoxic effects of intracanal medicaments. A Knowledge, Attitude and Practice based survey was conducted in January 2020 among dental students (Third years, Final years, Interns). The questionnaire consisted of 10 Knowledge, awareness and practice based questions and were equally distributed among Third years, Final years, Interns. The total sample size was 150 dental students. The data collected was entered in an Excel sheet and subjected to statistical analysis using SPSS version 20. From the responses obtained it was seen that 33.33\% of the interns had a knowledge of intracanal medicaments being used whereas only $26.67 \%$ of final years and 10\% of third years had a knowledge. 33.33\% of the interns had used an intracanal medicament on the patient and only $26.67 \%$ of final years and $4.67 \%$ of third years had used a medicament. $21.33 \%$ of the final years said that they use an intracanal medicament for all patients whereas $20.67 \%$ of interns and $4 \%$ of third years have given a response of yes. 30.67\% of interns, $22.67 \%$ of final years, $4.67 \%$ of third years knew the mechanism of action of the medicament. 33.33\% of interns, 33.33\% of final years and 8.67\% of third years were aware of the term cytotoxicity. Chi square test shows $\mathrm{p}<0.05$, significant. It was seen that Knowledge, awareness and practice on the cytotoxicity of intracanal medicaments was higher among interns, followed by the final years and then third years
\end{abstract}

\section{KEY WORDS: CALCIUM HYDROXIDE; CYTOTOXICITY; MEDICAMENTS; PERIAPICAL TISSUES.}

\section{INTRODUCTION}

The main goal of endodontic treatment is removal of bacteria along with its byproducts, and pulpal remnants from infected root canals and completely sealing of

\section{ARTICLE INFORMATION}

*Corresponding Author: delphine.sdc@saveetha.com Received 15th June 2020 Accepted after revision 9th August 2020 Print ISSN: 0974-6455 Online ISSN: 2321-4007 CODEN: BBRCBA

Thomson Reuters ISI Web of Science Clarivate Analytics USA and Crossref Indexed Journal

\section{Clarivate}

NAAS Journal Score 2020 (4.31) SJIF: 2020 (7.728)

A Society of Science and Nature Publication,

Bhopal India 2020. All rights reserved.

Online Contents Available at: http//www.bbrc.in/

Doi: http://dx.doi.org/10.21786/bbrc/13.7/17 disinfected root canals. Intracanal medicaments play an important role in killing the bacteria in root canals (Iftekhar, Kumar and Tamanna, 2019). To eliminate all the bacteria from the entire root canal system, a combination of mechanical instrumentation and irrigation should be used to remove or dissolve organic and inorganic debris, to destroy bacteria, to remove the smear layer and to maintain dentine permeability (Abbott, 1990). Postoperative pain is generally due to inflammation of the periradicular tissues caused by irritants egressing from the root canal during treatment. Calcium hydroxide intracanal medicament has been proven to have pain

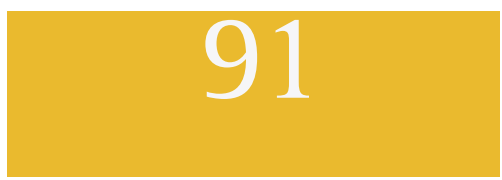


preventive properties because of its antimicrobial effects (Anjaneyulu and Nivedhitha, 2014).

Intracanal medicaments are made of various compounds like the phenolic compounds which includes crestatin, camphorated monochlorophenol and aldehydes that includes formocresol and glutaraldehyde, as well as other materials such as calcium hydroxide and some antibiotics (Johnson and Noblett, 2009) A successful outcome of root canal therapy relies on effective disinfection of the root canal system, including the use of intracanal medicaments, which vary in their bactericidal and cytotoxic properties (Selis et al., 2019). Intracanal medications need to be biocompatible as they come in direct contact with periapical tissues during endodontic treatment. These medications can be cytotoxic (de Paula Farias et al., 2016).

Calcium hydroxide is a commonly used intracanal medicament. Chlorhexidine gluconate $(2 \%)$ is now recommended as an effective alternative to calcium hydroxide (Basrani, Ghanem and Tjäderhane, 2004). Intracanal medicament speeds up the natural healing of periapical lesion, regardless of the bacterial status of the root canal at the time of placement of the material in the canal (Ellerbruch and Murphy, 1977; Peters et al., 2002) It possesses several advantages such as tissue dissolving ability (Hasselgren, Olsson and Cvek, 1988) and antibacterial properties (Siqueira and Lopes, 1999). Triple antibiotic paste (TAP) composed of ciprofloxacin, metronidazole, and minocycline is also being used as an effective intra canal medicament (Hoshino et al., 1996). This mixture has been used for disinfection of the root canal system during root canal treatment and pulpal regeneration (Özan and Er, 2005; Bose, Nummikoski and Hargreaves, 2009). One disadvantage of using this is that the minocycline present might cause discoloration of the teeth. In recent times, cefaclor has replaced minocycline in this paste, and the paste is called a modified triple antibiotic paste (mTAP). After canal disinfection and the medication period depending upon the condition of the tooth, the intracanal medicament should be removed from the root canal completely before the placement of the filling or repair material.

Cytotoxicity is a characteristic of being toxic to cells. When a cell gets exposed to a cytotoxic compound, it can result in various alterations in a cell. The cells then necrosis and lose its membrane integrity and die as a result of cell lysis. The cells can stop actively growing and dividing or the cells can activate a genetic program of controlled cell death known as apoptosis. Cells undergoing necrosis show rapid swelling, subsequently loses its membrane integrity, shut down all its metabolism and releases all its contents into the environment. Cells that undergo rapid necrosis in vitro do not have sufficient time or energy to activate its apoptotic machinery and doest express apoptotic markers. Cells in culture that are undergoing apoptosis eventually undergo secondary necrosis in the next step. They will shut down metabolism, lose membrane integrity and lyse the cell (Riss and Moravec, 2004).
Some endodontic intracanal medicaments which including camphorated Cresatin, para-monochlorophenol and Acriphen were tested for its cytotoxic effect and all three drugs showed extreme toxicity to the tissue culture cells even when the concentration of each drug was in a dilution of 1:1,000 (Kantz, Ferrillo and Zimmermann, 1974). Thus the efficient use of intracanal medicament needs to be highlighted in order to carry on safe and effective treatment without injuring any periapical tissues. Apical periodontitis, in the situations where the periapical tissues are injured is likely to occur and it is known as the inflammation of the periodontium caused by trauma, irritation or due to infection through the root canal, regardless of whether the pulp is vital or non-vital (Antony, Thomas and Nivedhitha, 2020).

We have numerous highly cited publications on well designed clinical trials and lab studies (Govindaraju, Neelakantan and Gutmann, 2017; Azeem and Sureshbabu, 2018; Jenarthanan and Subbarao, 2018; Manohar and Sharma, 2018; Nandakumar and Nasim, 2018; Teja, Ramesh and Priya, 2018; Janani and Sandhya, 2019; Khandelwal and Palanivelu, 2019; Malli Sureshbabu et al., 2019; Poorni, Srinivasan and Nivedhitha, 2019; Rajakeerthi and Ms, 2019; Rajendran et al., 2019; Ramarao and Sathyanarayanan, 2019; Siddique and Nivedhitha, 2019; Siddique et al., 2019; Siddique, Nivedhitha and Jacob, 2019). This has provided the right platforms for us to pursue the current study. Our aim is to assess the knowledge, attitude and practice among dental students on the cytotoxic effects of intracanal medicaments.

\section{MATERIAL AND METHODS}

Study design: Knowledge, Attitude and Practice based survey.

Data collection: A survey was conducted in January 2020 among dental students (Third years, Final years, Interns). It was an online questionnaire based study, conducted to assess the knowledge, attitude and practice of cytotoxicity of intracanal medicaments. 150 dental students (Third years, Final years, Interns) participated in this study. The data collection was done via google forms.

Survey instrument: A pretested, self administered, closed ended questionnaire comprising the following sections formed the survey instrument. A structured questionnaire containing 10 questions which was adopted from a validated questionnaire developed by the World Health Organisation. The questionnaire was equally distributed among Third years, Final years, Interns. The goal of developing this questionnaire was to know about the knowledge the dental students had on intracanal medicaments and its cytotoxic behaviour. The questions had to be answered with a Yes or No response.

Ethical approval: Ethical approval was obtained from the Institutional Ethical Committee. 
Data analysis: The data collected was entered in Excel sheet and subjected to statistical analysis using SPSS version 20. Chi square test was done. The independent variables are age and gender while dependent variables are knowledge, attitude and practice of cytotoxicity of intra canal medicaments. The level of significance was set at $\mathrm{p}<0.05$.

\section{Questionnaire given is as follows: Year of study:}

1. Do you know the available intracanal medicaments that are being used?

2. Have you used an intracanal medicament on the patient?

3. Do you use a medicament for all patients undergoing root canal treatment?

4. Do you know the mechanism of action of the medicament that you use?

5. Are you aware of the term cytotoxicity?

6. Do you place an intracanal medicament more than 2 weeks?

7. Do you take swabs/ radiographs to ensure the activity of the medicament?

8. Have you faced any complication that has arised due to placement of the medicament for a long duration into the root canal?

9. Do you know the cytotoxic effects of the medicaments that are being used?

10. Are you aware of the procedure on management of cytotoxic effect of produced by intracanal medicaments?

\section{RESULTS AND DISCUSSION}

From the responses obtained it was seen that 33.33\% of the interns had a knowledge of intracanal medicaments being used whereas only $26.67 \%$ of final years and 10\% of third years had a knowledge, Chi square test shows $\mathrm{p}=0.000$, significant (Figure 1). $33.33 \%$ of the interns had used an intracanal medicament on the patient and only $26.67 \%$ of final years and $4.67 \%$ of third years had used a medicament, Chi square test shows $\mathrm{p}=0.000$, significant (Figure 2). 21.33\% of the final years said that they use an intracanal medicament for all patients whereas $20.67 \%$ of interns and 4\% of third years have given a response of yes, Chi square test shows $\mathrm{p}=0.000$, significant (Figure 3 ). $30.67 \%$ of interns, $22.67 \%$ of final years, $4.67 \%$ of third years knew the mechanism of action of the medicament (Figure 4). 33.33\% of interns, 33.33\% of final years and $8.67 \%$ of third years were aware of the term cytotoxicity, Chi square test shows $\mathrm{p}=0.000$, significant (Figure 5). $30.67 \%$ of interns, $32 \%$ of final years and $29.33 \%$ of third years have never placed an intracanal medicament more than 2 weeks, Chi square test shows $p=0.337$, not significant (Figure 6).

$22 \%$ of interns,32\% of final years and $30.67 \%$ of third years never take a swab or a radiograph to ensure the activity of the medicament, Chi square test shows $p=0.000$, significant (Figure 7). 26.67\% of interns, 31.22\% of final years and $30.67 \%$ of third years have never faced a complication due to long duration of placement of the medicaments, Chi square test shows $\mathrm{p}=0.058$, not significant (Figure 8). 31.33\% of interns, 27.33\% of final years and $12 \%$ of third years were aware of the cytotoxic effects of the medicament being used, Chi square test shows $\mathrm{p}=0.000$, significant (Figure 9). 6\% of the interns, 30\% of the final years and 33.33\% of the third years weren't aware of the procedure of management of the cytotoxic effects produced, Chi square test shows $\mathrm{p}=0.000$, significant (Figure 10).

Figure 1: Bar graph denotes association between year of study of the participants and number of students who have knowledge on the available intracanal medicaments. $\mathrm{X}$ axis denotes the year of study of the participants and $\mathrm{Y}$ axis denotes the number of dental students. Majority of the interns have given a response of yes (green) and majority of the third years have given a response of no (blue). Chi square test shows $\mathrm{p}=\mathbf{0 . 0 0 0}$, significant. Hence proving that there is significant association between the year of study of the participants and number of dental students who have knowledge on the available intracanal medicaments

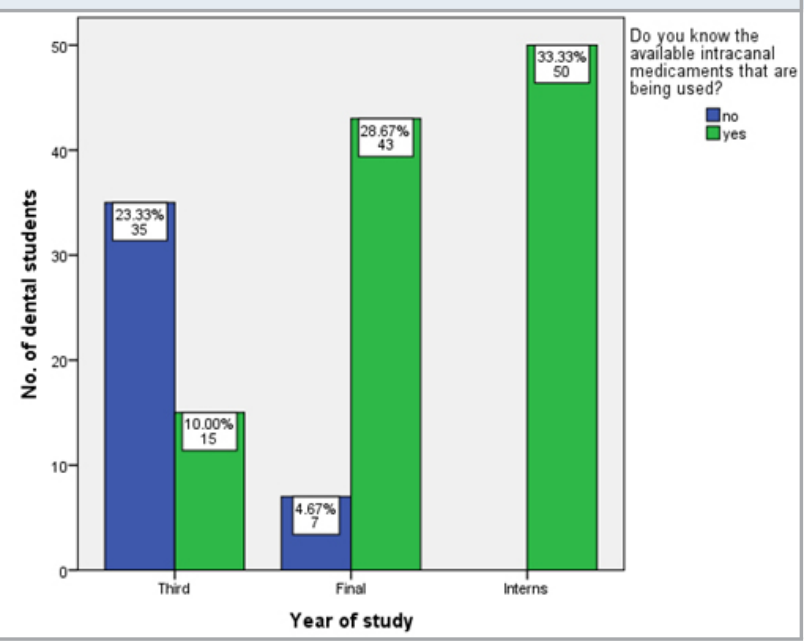

It was seen that in our study $33.33 \%$ of the interns had a knowledge of intracanal medicaments being used whereas only $26.67 \%$ of final years and $10 \%$ of third years had a knowledge. It was said that Intracanal medicaments have traditionally gone hand-in-glove with endodontics. They are generally considered to be an integral part of treatment and important to the success of root canal therapy (Yassen, Eckert and Platt, 2015; Afkhami et al., 2019). Various other medicaments like calcium hydroxide, phenolic preparations, formaldehyde, chlorhexidine (CHX), halogens, and steroids preparation are also being used nowadays (Iftekhar, Kumar and Tamanna, 2019). 33.33\% of the interns had used an intracanal medicament on the patient and only $26.67 \%$ of final years and $4.67 \%$ of third years had used a medicament in the study conducted. In contaminated canals generally placement of an intracanal dressing to the full length of the canal is the treatment of choice. Intracanal medication is placed in teeth with large 
periapical lesions and in cases where it is necessary to control the passage of periapical exudates into the canal (Tanomarufilho, Leonardo and Bezerradasilva, 2002).

Figure 2: Bar graph denotes association between year of study of the participants and number of students who have used an intracanal medicament. $\mathrm{X}$ axis denotes the year of study of the participants and $\mathrm{Y}$ axis denotes the number of dental students. Majority of the interns have given a response of yes (green) and majority of the third years have given a response of no (blue). Chi square test shows $\mathrm{p}=0.000$, significant. Hence proving that there is significant association between the year of study of the participants and number of dental students who have used an intracanal medicament

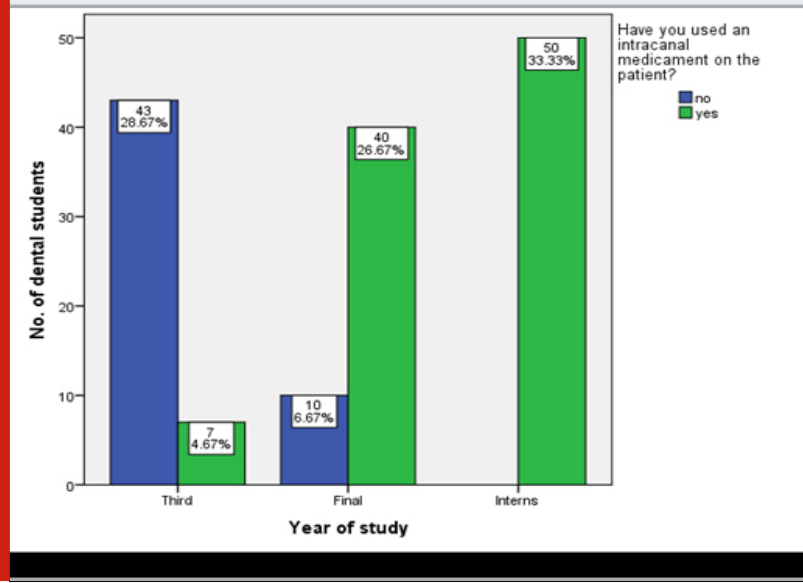

Figure 3: Bar graph denotes association between year of study of the participants and number of students who use an intracanal medicament for all patients. $X$ axis denotes the year of study of the participants and $Y$ axis denotes the number of dental students. Majority of the interns have given a response of yes (green) and majority of the third years have given a response of no (blue). Chi square test shows $\mathrm{p}=0.000$, significant. Hence proving that there is significant association between the year of study of the participants and number of dental students who use an intracanal medicament for all patients

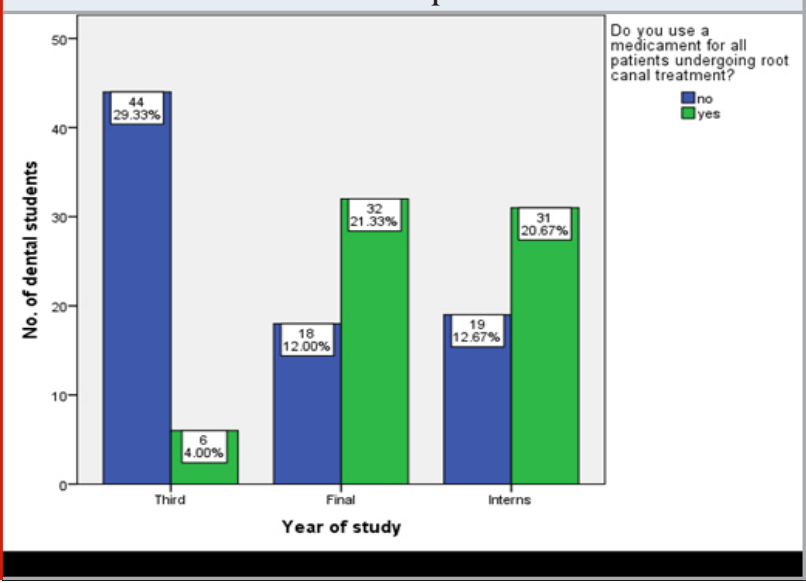

Figure 4: Bar graph denotes association between year of study of the participants and number of students who had knowledge on the mechanism of action of the medicaments. $\mathrm{X}$ axis denotes the year of study of the participants and $\mathrm{Y}$ axis denotes the number of dental students. Majority of the interns have given a response of yes (green) and majority of the third years have given a response of no (blue). Chi square test shows $\mathrm{p}=\mathbf{0 . 0 0 0}$, significant. Hence proving that there is significant association between the year of study of the participants and number of dental students who had knowledge on the mechanism of action of the medicaments

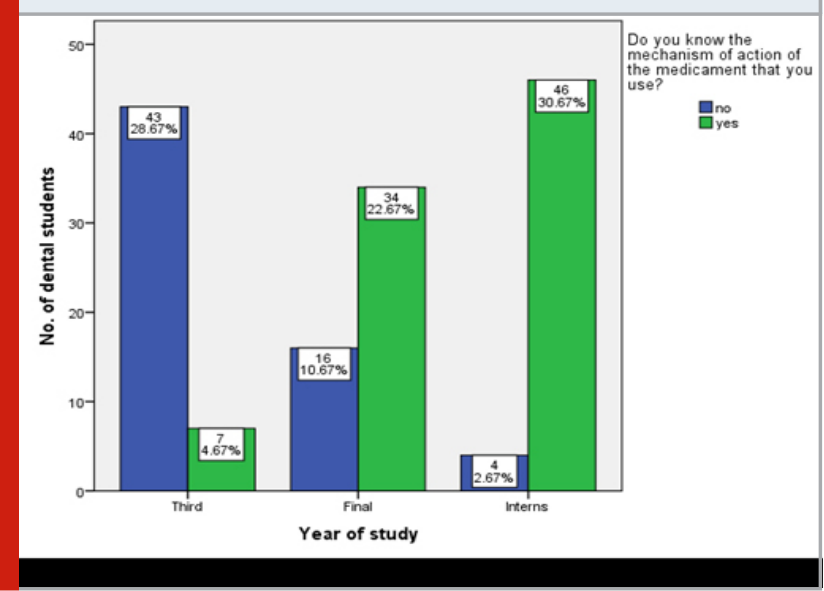

Figure 5: Bar graph denotes association between year of study of the participants and number of students who are aware of the term cytotoxicity. $\mathrm{X}$ axis denotes the year of study of the participants and $\mathrm{Y}$ axis denotes the number of dental students. Majority of the interns and final years have given a response of yes (green) and majority of the third years have given a response of no (blue). Chi square test shows $\mathrm{p}=\mathbf{0 . 0 0 0}$, significant. Hence proving that there is significant association between the year of study of the participants and number of dental students who are aware of the term cytotoxicity

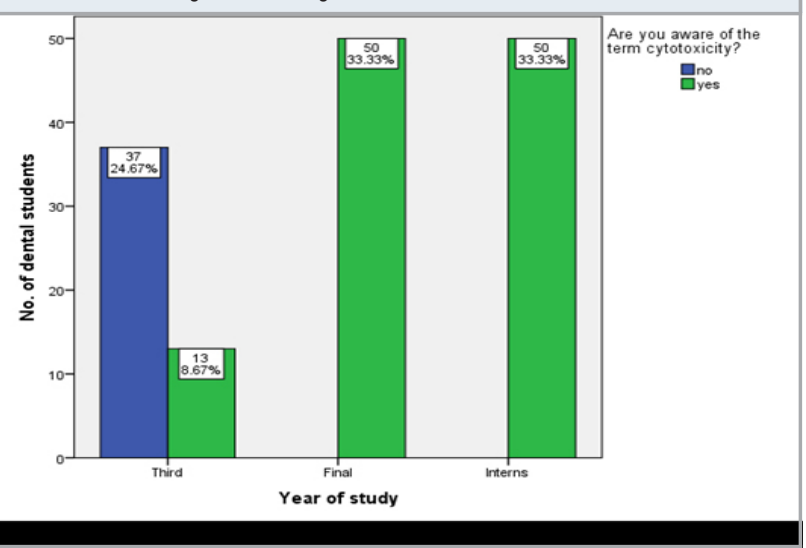

In our study, $21.33 \%$ of the final years said that they use an intracanal medicament for all patients whereas $20.67 \%$ of interns and $4 \%$ of third years have said a yes. Intracanal dressing is mostly indicated in teeth with a 
large periapical lesion and where there is a necessity to control the passage of periapical exudates into the canal (Tanomarufilho, Leonardo and Bezerradasilva, 2002). Ahamad et al. stated that the proportion of those who used Intra canal medicaments after cleaning and shaping of vital cases (65.1\%) was significantly greater than that of those who did not do so (34.9\%) (Madarati et al., 2017).From our results, $30.67 \%$ of interns, $22.67 \%$ of final years, $4.67 \%$ of third years knew the mechanism of action of the medicament. Studies prove that intra canal medicaments are used to relieve inflammation of pulpal or periapical tissues, to neutralize tissue debris, and to obstruct microleakage from temporary restorations and dry weeping canals (Chong and Pitt Ford, 1992).

Figure 6: Bar graph denotes association between year of study of the participants and number of students who place an intracanal medicament more than 2 weeks. $X$ axis denotes the year of study of the participants and $Y$ axis denotes the number of dental students. Majority of the third years have given a response of yes (green) and majority of the final years have given a response of no (blue). Chi square test shows $\mathrm{p}=0.337$, not significant. Hence proving that there is no significant association between the year of study of the participants and number of students who place an intracanal medicament more than 2 weeks

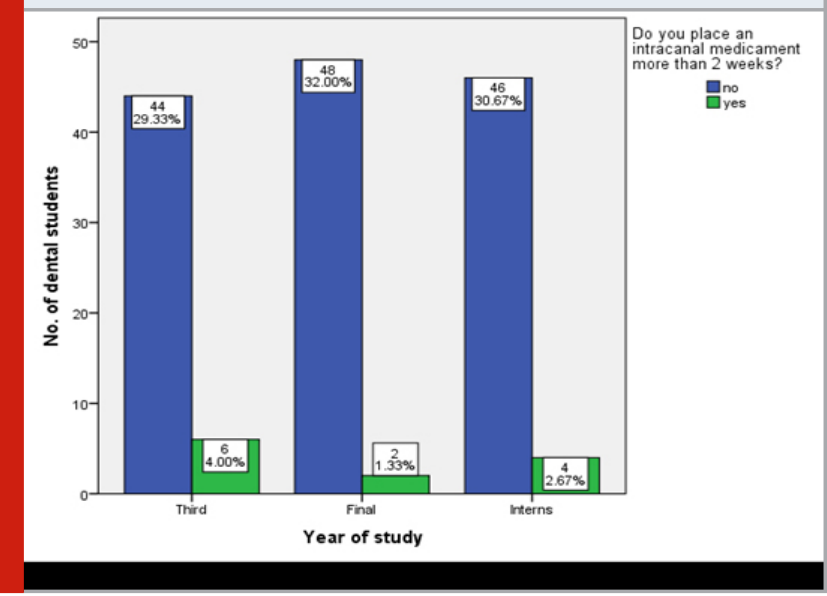

The medicament should only be used for root canal disinfection as a secondary to mechanical cleaning and shaping (Chong and Pitt Ford, 1992; Kawashima et al., 2009). Highest proportion of respondents (53.7\%) used the medicaments for the disinfection of root canals (Madarati et al., 2017). From our results it was seen that $33.33 \%$ of interns, $33.33 \%$ of final years and $8.67 \%$ of third years were aware of the term cytotoxicity. It was seen that most third years were not aware of the term as being newly introduced to clinical subjects it requires experience and time to get used to terms and clinical case managements.

In our study, 30.67\% of interns, 32\% of final years and $29.33 \%$ of third years have never placed an intracanal medicament more than 2 weeks. Chong et al highlighted the application of intracanal medicament for asepsis control and disinfection of infected root canals (Chong and Pitt Ford, 1992). From the results obtained it was seen that $22 \%$ of interns, $32 \%$ of final years and $30.67 \%$ of third years never take a swab or a radiograph to ensure the activity of the medicament. Failure of endodontically treated teeth is usually caused by opportunistic or more resistant microorganisms such as Enterococcus faecalis, Candida albicans. Considering the existence of resistant strains in failed endodontic cases, most endodontists relied on calcium hydroxide (79\%) and antibiotics (21\%) (Madarati et al., 2017).

Figure 7: Bar graph denotes association between year of study of the participants and number of dental students who take swabs/radiographs to ensure the activity of the medication. $\mathrm{X}$ axis denotes the year of study of the participants and $\mathrm{Y}$ axis denotes the number of dental students. Majority of the interns have given a response of yes (green) and majority of the final years have given a response of no (blue). Chi square test shows $p=0.000$, significant. Hence proving that there is significant association between year of study of the participants and number of dental students who take swabs/radiographs to ensure the activity of the medication

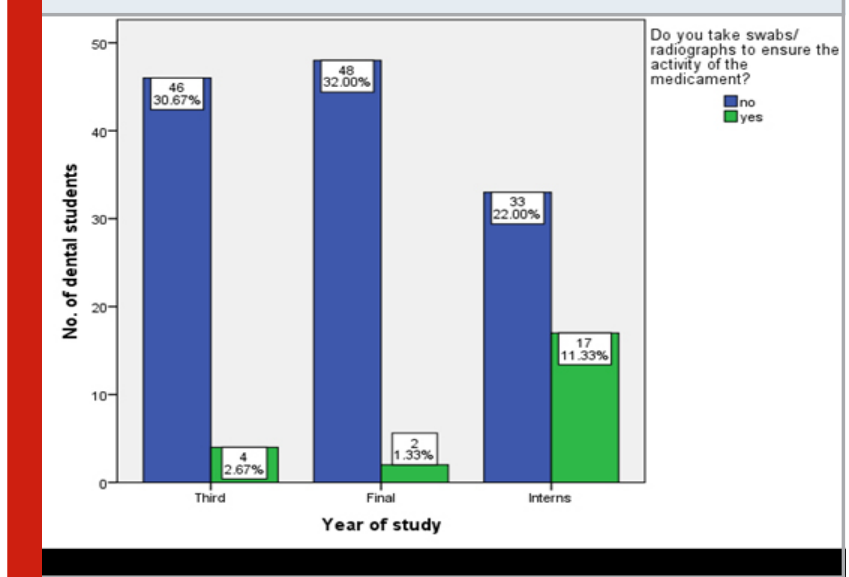

In our study conducted, 26.67\% of interns, 31.22\% of final years and $30.67 \%$ of third years have never faced a complication due to long duration of placement of the medicaments. In vitro studies have proved that dentin can inactivate the antibacterial activity of Calcium hydroxide. It is seen that the number of bacterial colonies in the canals increased even after 1 week of placing calcium hydroxide within the canal. Studies have also indicated that Calcium hydroxide could not predictably eliminate bacteria or that cultures changed from negative to positive after placement of calcium hydroxide intracanal medicament (Peters et al., 2002; Waltimo et al., 2005).

$31.33 \%$ of interns, $27.33 \%$ of final years and 12\% of third years were aware of the cytotoxic effects of the medicament being used in our study. Allergic reactions, anaphylactic shock, contact dermatitis, urticaria have been reported following direct contact of medicament to mucosal tissue or open wounds (Okano et al., 1989). When looking into the potential toxicity of surviving cells in the periapical region there is major concern as 
these medicaments are in direct contact with periapical tissue and a cytotoxic medicament can lead to DNA damage of conjunctive cells eventually leading to prevention and retardation of healing along with other phenotypic changes which damages the tooth or either causes root anal failure (Geurtsen and Leyhausen, 1997). Placement of intracanal medicament in root canals that contain vital pulp tissue as these are not infected before instrumentation or in contaminated canals which are cleaned and shaped with proper instrumentation technique is said to not require medicaments. However, if a root canal is heavily infected before instrumentation, it is highly probable that a few bacteria will remain (Tanomarufilho, Leonardo and Bezerradasilva, 2002; Zerella, Fouad and Spångberg, 2005).

Figure 8:Bar graph denotes association between year of study of the participants and number of dental students who have faced a complication due to placement of the medicament into the root canal for a longer duration. $\mathrm{X}$ axis denotes the year of study of the participants and $Y$ axis denotes the number of dental students. Majority of the interns have given a response of yes (green) and majority of the final years have given a response of no (blue). Chi square test shows $\mathrm{p}=0.058$, not significant. Hence proving that there is no significant association between year of study of the participants and number of dental students who have faced a complication due to placement of the medicament into the root canal for a longer duration

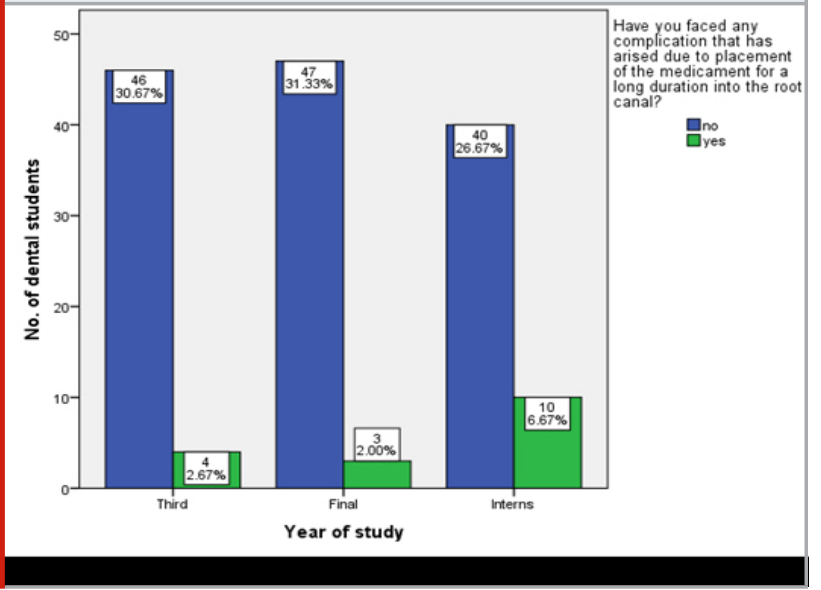

From our results, $6 \%$ of the interns, $30 \%$ of the final years and $33.33 \%$ of the third years weren't aware of the procedure of management of the cytotoxic effects produced. Root canal medicaments should be biocompatible since they may get in contact with the periapical tissues. The direct contact and the medicament over time could induce cytotoxic damage to cells and tissues and subsequently affect the outcome of the root canal treatment if placed for a very long period of time (Peters et al., 2002; Basrani et al., 2003).

Thus it is recommended to use medicaments of proper composition and placement only for the required period of time and not more than that (generally not preferred more than 2 weeks). In case of placement beyond the required time, a radiograph or a swab can be taken to ensure that periapical tissues are not damaged. In certain cases the tooth might require Nonsurgical management if the damage is extreme (Fernandes and Ataide, 2010). Analysing the benefits and risks associated with the use of these medicaments is of extreme importance most specifically in regenerative endodontic procedures because the residual stem cells may get damaged (Selis et al., 2019).

Figure 9: Bar graph denotes association between year of study of the participants and number of dental students who are aware of the cytotoxicity of the medicament they use. $\mathrm{X}$ axis denotes the year of study of the participants and $\mathrm{Y}$ axis denotes the number of dental students. Majority of the interns have given a response of yes (green) and majority of the third years have given a response of no (blue). Chi square test shows $p=0.000$, significant. Hence proving that there is significant association between the year of study of the participants and number of dental students who are aware of the cytotoxicity of the medicament they use

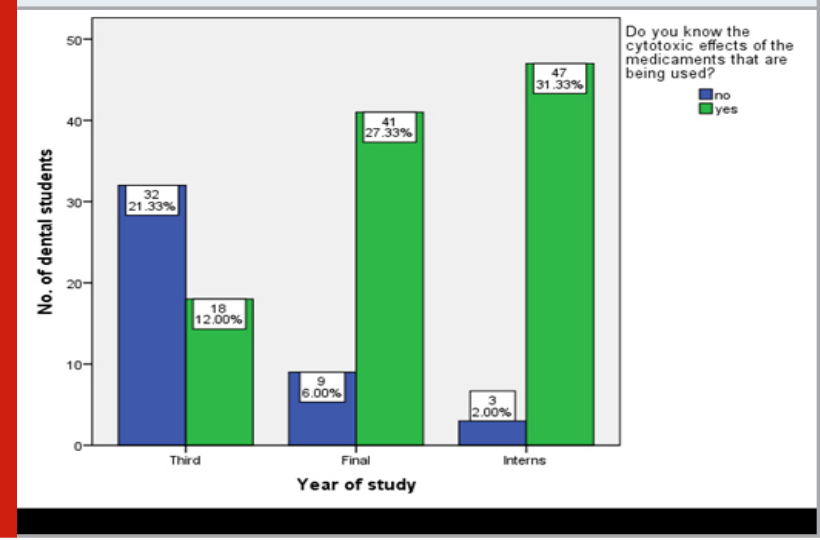

Figure 10: Bar graph denotes association between year of study of the participants and number of dental students who are aware of the method to manage the cytotoxic effects produced by the medicament. $\mathrm{X}$ axis denotes the year of study of the participants and $\mathrm{Y}$ axis denotes the number of dental students. Majority of the interns have given a response of yes (green) and majority of the third years have given a response of no (blue). Chi square test shows $\mathrm{p}=0.000$, significant. Hence proving that there is significant association between the year of study of the participants and number of dental students who are aware of the method to manage the cytotoxic effects produced by the medicament

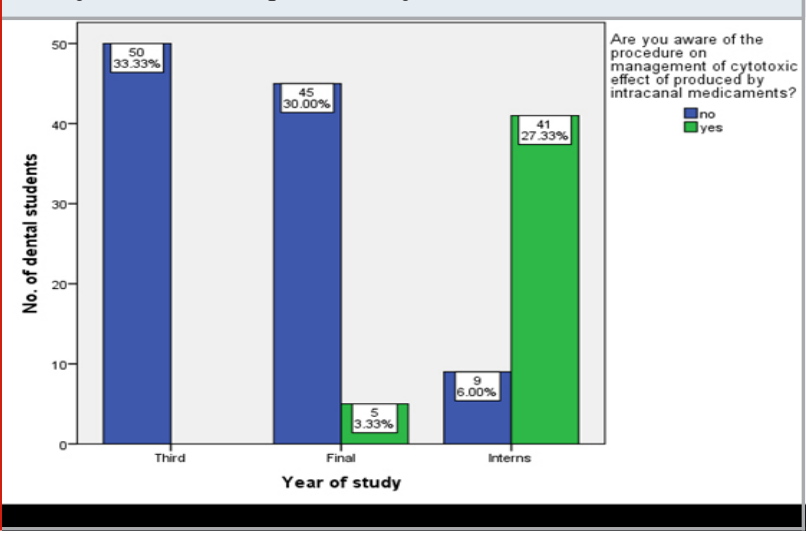


Knowledge on the available intracanal medicaments would help the practitioners to use the apt material as an intracanal medicaments in every different clinical situations (Manohar and Sharma, 2018). The limitation was the study is that the study was conducted only in one city (Chennai) and may not be generalized to other regions.

\section{CONCLUSION}

Within the limitations of the study it was seen that Knowledge, awareness and practice on the cytotoxicity of intracanal medicaments was higher among interns, followed by the final years and then third years. This is because of the clinical expertise that the interns have acquired through clinical experience and clinical practice.

\section{ACKNOWLEDGEMENTS}

I would like to thank Saveetha Dental College and Hospital for supporting this study and the reviewers of the study for their valuable contribution.

Conflict of interest: Authors have no conflict of interest

\section{REFERENCES}

Abbott, P. V. (1990) 'Medicaments: aids to success in endodontics. Part 1. A review of the literature', Australian dental journal, 35(5), pp. 438-448.

Afkhami, F. et al. (2019) 'Discoloration of teeth due to different intracanal medicaments', Restorative Dentistry Et Endodontics. doi: 10.5395/rde.2019.44.e10.

Anjaneyulu, K. and Nivedhitha, M. S. (2014) 'Influence of calcium hydroxide on the post-treatment pain in Endodontics: A systematic review', Journal of conservative dentistry: JCD, 17(3), pp. 200-207.

Antony, D. P., Thomas, T. and Nivedhitha, M. S. (2020) 'Two-dimensional Periapical, Panoramic Radiography Versus Three-dimensional Cone-beam Computed Tomography in the Detection of Periapical Lesion After Endodontic Treatment: A Systematic Review', Cureus, 12(4), p. e7736.

Azeem, R. A. and Sureshbabu, N. M. (2018) 'Clinical performance of direct versus indirect composite restorations in posterior teeth: A systematic review', Journal of conservative dentistry: JCD, 21(1), pp. 2-9. Basrani, B. et al. (2003) 'Efficacy of chlorhexidineand calcium hydroxide-containing medicaments against Enterococcus faecalis in vitro', Oral Surgery, Oral Medicine, Oral Pathology, Oral Radiology, and Endodontology, 96(5), pp. 618-624.

Basrani, B., Ghanem, A. and Tjäderhane, L. (2004) 'Physical and chemical properties of chlorhexidine and calcium hydroxide-containing medications', Journal of endodontia, 30(6), pp. 413-417.

Bose, R., Nummikoski, P. and Hargreaves, K. (2009) 'A retrospective evaluation of radiographic outcomes in immature teeth with necrotic root canal systems treated with regenerative endodontic procedures', Journal of endodontia, 35(10), pp. 1343-1349.

Chong, B. S. and Pitt Ford, T. R. (1992) 'The role of intracanal medication in root canal treatment', International endodontic journal, 25(2), pp. 97-106.

Ellerbruch, E. S. and Murphy, R. A. (1977) 'Antimicrobial activity of root canal medicament vapors', Journal of endodontia, 3(5), pp. 189-193.

Fernandes, M. and Ataide, I. (2010) 'Nonsurgical management of periapical lesions', Journal of Conservative Dentistry, p. 240. doi: 10.4103/09720707.73384

Geurtsen, W. and Leyhausen, G. (1997) 'Biological aspects of root canal filling materials - histocompatibility, cytotoxicity, and mutagenicity', Clinical Oral Investigations, pp. 5-11. doi: 10.1007/s007840050002. Govindaraju, L., Neelakantan, P. and Gutmann, J. L. (2017) 'Effect of root canal irrigating solutions on the compressive strength of tricalcium silicate cements', Clinical oral investigations, 21(2), pp. 567-571.

Hasselgren, G., Olsson, B. and Cvek, M. (1988) 'Effects of calcium hydroxide and sodium hypochlorite on the dissolution of necrotic porcine muscle tissue', Journal of endodontia, 14(3), pp. 125-127.

Hoshino, E. et al. (1996) 'In-vitro antibacterial susceptibility of bacteria taken from infected root dentine to a mixture of ciprofloxacin, metronidazole and minocycline', International Endodontic Journal, pp. 125-130. doi: 10.1111/j.1365-2591.1996.tb01173.x.

Iftekhar, H., Kumar, A. and Tamanna, S. (2019) 'Intracanal medicaments - Their use in modern endodontics: A narrative review', Journal of Oral Research and Review, p. 94. doi: 10.4103/jorr.jorr_3_19.

Janani, K. and Sandhya, R. (2019) 'A survey on skills for cone beam computed tomography interpretation among endodontists for endodontic treatment procedure', Indian journal of dental research: official publication of Indian Society for Dental Research, 30(6), pp. 834-838.

Jenarthanan, S. and Subbarao, C. (2018) 'Comparative evaluation of the efficacy of diclofenac sodium administered using different delivery routes in the management of endodontic pain: A randomized controlled clinical trial', Journal of conservative dentistry: JCD, 21(3), pp. 297-301.

Johnson, W. T. and Noblett, W. C. (2009) 'Cleaning and shaping in: endodontics: principles and practice', Torabinejad M, Walton RE, editors, 2009, pp. 264265.

Kantz, W. E., Ferrillo, P. J. and Zimmermann, E. R. (1974) 'Cytotoxicity of three endodontic intracanal medicaments', Oral surgery, oral medicine, and oral pathology, 38(4), pp. 600-604.

Kawashima, N. et al. (2009) 'Root canal medicaments', International dental journal, 59(1), pp. 5-11.

Khandelwal, A. and Palanivelu, A. (2019) 'Correlation 
Between Dental Caries And Salivary Albumin In Adult Population In Chennai: An In Vivo Study', Brazilian Dental Science, 22(2), pp. 228-233.

Madarati, A. A. et al. (2017) 'Preference and usage of intracanal medications during endodontic treatment', Saudi medical journal, 38(7), pp. 755-763.

Malli Sureshbabu, N. et al. (2019) 'Concentrated Growth Factors as an Ingenious Biomaterial in Regeneration of Bony Defects after Periapical Surgery: A Report of Two Cases', Case reports in dentistry, 2019, p. 7046203. Manohar, M. P. and Sharma, S. (2018) 'A survey of the knowledge, attitude, and awareness about the principal choice of intracanal medicaments among the general dental practitioners and nonendodontic specialists', Indian journal of dental research: official publication of Indian Society for Dental Research, 29(6), pp. 716-720.

Nandakumar, M. and Nasim, I. (2018) 'Comparative evaluation of grape seed and cranberry extracts in preventing enamel erosion: An optical emission spectrometric analysis', Journal of conservative dentistry: JCD, 21(5), pp. 516-520.

Okano, M. et al. (1989) 'Anaphylactic symptoms due to chlorhexidine gluconate', Archives of dermatology, 125(1), pp. 50-52.

Özan, Ü. and Er, K. (2005) 'Endodontic Treatment of a Large Cyst-Like Periradicular Lesion Using a Combination of Antibiotic Drugs: A Case Report', Journal of Endodontics, pp. 898-900. doi: 10.1097/01. don.0000164129.74235.8e.

de Paula Farias, M. et al. (2016) 'Assessment of intracanal medications cytotoxicity on L929 fibroblast cells', Bioscience Journal, 32(2). doi: 10.14393/BJv32n2a2016-30974.

Peters, L. B. et al. (2002) 'Effects of instrumentation, irrigation and dressing with calcium hydroxide on infection in pulpless teeth with periapical bone lesions', International endodontic journal, 35(1), pp. 13-21.

Poorni, S., Srinivasan, M. R. and Nivedhitha, M. S. (2019) 'Probiotic strains in caries prevention: A systematic review', Journal of conservative dentistry: JCD, 22(2), pp. 123-128.

Rajakeerthi, R. and Ms, N. (2019) 'Natural Product as the Storage medium for an avulsed tooth - A Systematic Review', Cumhuriyet Dental Journal, 22(2), pp. 249256.

Rajendran, R. et al. (2019) 'Comparative Evaluation of Remineralizing Potential of a Paste Containing Bioactive Glass and a Topical Cream Containing Casein Phosphopeptide-Amorphous Calcium Phosphate: An in Vitro Study', Pesquisa brasileira em odontopediatria e clinica integrada, 19(1), pp. 1-10.

Ramarao, S. and Sathyanarayanan, U. (2019) 'CRA Grid - A preliminary development and calibration of a paper-based objectivization of caries risk assessment in undergraduate dental education', Journal of conservative dentistry: JCD, 22(2), pp. 185-190. Riss, T. L. and Moravec, R. A. (2004) 'Use of multiple assay endpoints to investigate the effects of incubation time, dose of toxin, and plating density in cell-based cytotoxicity assays', Assay and drug development technologies, 2(1), pp. 51-62.

Selis, D. et al. (2019) 'Cytotoxicity and Genotoxicity of a New Intracanal Medicament, 2-hydroxyisocaproic Acid-An In Vitro Study', Journal of endodontia, 45(5), pp. 578-583.

Siddique, R. et al. (2019) 'Qualitative and quantitative analysis of precipitate formation following interaction of chlorhexidine with sodium hypochlorite, neem, and tulsi', Journal of conservative dentistry: JCD, 22(1), pp. 40-47.

Siddique, R. and Nivedhitha, M. S. (2019) 'Effectiveness of rotary and reciprocating systems on microbial reduction: A systematic review', Journal of conservative dentistry: JCD, 22(2), pp. 114-122.

Siddique, R., Nivedhitha, M. S. and Jacob, B. (2019) 'Quantitative analysis for detection of toxic elements in various irrigants, their combination (precipitate), and para-chloroaniline: An inductively coupled plasma mass spectrometry study', Journal of conservative dentistry: JCD, 22(4), pp. 344-350.

Siqueira, J. F., Jr and Lopes, H. P. (1999) 'Mechanisms of antimicrobial activity of calcium hydroxide: a critical review', International endodontic journal, 32(5), pp. 361-369.

Tanomarufilho, M., Leonardo, M. and Bezerradasilva, L. (2002) 'Effect of Irrigating Solution and Calcium Hydroxide Root Canal Dressing on the Repair of Apical and Periapical Tissues of Teeth with Periapical Lesion', Journal of Endodontics, pp. 295-299. doi: 10.1097/00004770-200204000-00009.

Teja, K. V., Ramesh, S. and Priya, V. (2018) 'Regulation of matrix metalloproteinase-3 gene expression in inflammation: A molecular study', Journal of conservative dentistry: JCD, 21(6), pp. 592-596.

Waltimo, T. et al. (2005) 'Clinical Efficacy of Treatment Procedures in Endodontic Infection Control and One Year Follow-Up of Periapical Healing', Journal of Endodontics, pp. 863-866. doi: 10.1097/01. don.0000164856.27920.85.

Yassen, G. H., Eckert, G. J. and Platt, J. A. (2015) 'Effect of intracanal medicaments used in endodontic regeneration procedures on microhardness and chemical structure of dentin', Restorative Dentistry \&t Endodontics, p. 104. doi: 10.5395/rde.2015.40.2.104.

Zerella, J. A., Fouad, A. F. and Spångberg, L. S. W. (2005) 'Effectiveness of a calcium hydroxide and chlorhexidine digluconate mixture as disinfectant during retreatment of failed endodontic cases', Oral surgery, oral medicine, oral pathology, oral radiology, and endodontics, 100(6), pp. 756-761. 